\title{
Synthesis of nano Mn-Zn ferrites by gel combustion method with three different fuels and investigation of their structure and properties
}

\author{
Nima VAhDATI ${ }^{1}$, ARMAN SEDGHI ${ }^{2, *}$ \\ ${ }^{1}$ Department of Materials Science and Engineering, College of Engineering, Saveh Branch, Islamic Azad University, Saveh, \\ Iran \\ ${ }^{2}$ Materials Engineering Department, Imam Khomeini International University, Qazvin 34148 - 96818, Iran
}

\begin{abstract}
The purpose of studying the properties of zinc-manganese nanoferrite was to compare organic fuels that were produced in conditions created by the auto gel combustion method, using citric acid, glycine, and urea with different $\mathrm{pH}$ values: (citric acid $=6$, glycine $=3$ and urea $=0$ ). The samples were prepared in stoichiometric ratios to gain $\mathrm{Mn}_{0.5} \mathrm{Zn}_{0.5} \mathrm{Fe}_{2} \mathrm{O}_{4}$, and all the samples were calcined in the same condition $\left(500{ }^{\circ} \mathrm{C}\right.$ and 30 minutes). It should be noted that the entire process of synthesis was photographed to analyze the effect of fuels during the combustion process. Combustion reactions were studied by simultaneous thermal analysis (STA), FT-IR spectroscopy, and X-ray diffraction (XRD), also the Rietveld method was used to determine the type and amount of crystalline phases. Magnetic properties of the samples were measured by vibration sample magnetometer (VSM), and their morphology and powder agglomeration was observed by field emission scanning electron microscopy (FE-SEM) and transmission electron microscopy (TEM). Superior magnetic properties of the sample synthesized with glycine were achieved. Urea gave the smallest particle size, while citric acid produced intermediate properties.
\end{abstract}

Keywords: nanoferrite; gel combustion; fuel; magnetic properties; agglomeration; morphology.

\section{Introduction}

These days, extensive application of nanotechnology, especially in the field of nanomagnets production for magnetic separation, has been significantly progressed. For these applications, nanoparticles with ferrite spinel structure because of their magnetic behavior are one of the best candidates [1]. Manganese-zinc ferrites (MZF) due to their high magnetization and high Curie temperature are considered as the most appropriate nanomagnetic material [2]. Nanoparticles are fabricated by different methods, and between them, the gel combustion method is the fast and low-cost one. The gel combustion method used for the synthesis of manganese-zinc ferrites is an exothermic reaction. Nitrate salts were used according to calculations based on valence numbers of reacting elements [3]. Organic fuels were used as a reducing

*E-mail: sedghi@eng.ikiu.ac.ir agent for the reaction [4]. The synthesis method has affected the properties of ferrite nanoparticles [5]. Therefore, it is essential to choose a suitable fuel to improve chemical reaction [6]. The fuels, such as citric acid, glycine, and urea, are the most appropriate fuels which can be used for the synthesis of nanoparticles [7-9]. Typically, an exothermic reaction occurs very fast, and the rate of this reaction affects the nanoparticle size and morphology [10]. On the other hand, various factors such as particle size and surface to volume ratio affect the magnetic properties of manganese-zinc ferrite nanoparticles [11]. Some oxide ceramics, due to properties such as unparalleled spin of electrons, chemical stability, and electrical resistance, are classified as magnetic materials [12]. Glycine, which is used as a fuel in the process of nanoparticle synthesis, is compatible with the environment [13]. To produce high purity nanoparticles by combustion synthesis, a homogeneous chemical reaction with a low reaction rate must be employed. These 
types of reactions reduce heat decomposition temperature and lead to better particle size distribution [14-18]. The presence of ferric ions in sites of $\mathrm{A}$ and $\mathrm{B}$ affects the magnetic field, and according to that, the size of the ion modifies the magnetic properties [19]. The transition of cations to other sites caused by thermal treatment and ionic substitution [20] as well as redistribution of cations or substitution of other ions may enhance or reduce the physical properties [21]. The role of cation distribution on magnetic properties is significant [22]. The need to carry out a heat treatment to improve the purity of the final material is a major limitation of the sol-gel method [23]. This paper reports the results of experiments on the synthesis of $\mathrm{Mn}-\mathrm{Zn}$ ferrite nanoparticles by sol-gel combustion method with the use of three fuels, including citric acid, glycine and urea and their effect on the phase structure, morphology, size and magnetic properties of produced nanoparticles.

\section{Experimental}

To produce the nanoparticles, raw materials, including nitrate salts and organic matter as a fuel, produced by Merck Germany (all $>99 \%$ purity), were used. The nominal composition of $\mathrm{Mn}_{0.5} \mathrm{Zn}_{0.5} \mathrm{Fe}_{2} \mathrm{O}_{4}$ ferrite nanoparticles was prepared by the sol-gel auto-combustion method from the solutions of $\left(\mathrm{Fe}\left(\mathrm{NO}_{3}\right)_{3} \cdot 9 \mathrm{H}_{2} \mathrm{O}\right)$, $\left(\mathrm{Mn}\left(\mathrm{NO}_{3}\right)_{2} \cdot 4 \mathrm{H}_{2} \mathrm{O}\right),\left(\mathrm{Zn}\left(\mathrm{NO}_{3}\right)_{2} \cdot 6 \mathrm{H}_{2} \mathrm{O}\right)$ and different fuels including citric acid: $\mathrm{C}_{6} \mathrm{H}_{8} \mathrm{O}_{7} \cdot \mathrm{H}_{2} \mathrm{O}$, glycine: $\mathrm{C}_{2} \mathrm{H}_{5} \mathrm{NO}_{2}$ and urea: $\left.\mathrm{CO}\left(\mathrm{NH}_{2}\right)_{2}\right)$. Ammonia solution was added at a constant rate in combination with citric acid to achieve $\mathrm{pH}$ 6. The reactions were carried out according to the following scheme:

$$
\begin{aligned}
& 2.22 \mathrm{C}_{6} \mathrm{H}_{8} \mathrm{O}_{7} \cdot \mathrm{H}_{2} \mathrm{O}+0.5 \mathrm{Mn}\left(\mathrm{NO}_{3}\right)_{2} \cdot 4 \mathrm{H}_{2} \mathrm{O} \\
& +2 \mathrm{Fe}\left(\mathrm{NO}_{3}\right)_{3} \cdot 9 \mathrm{H}_{2} \mathrm{O}+0.5 \mathrm{Zn}\left(\mathrm{NO}_{3}\right)_{2} \cdot 6 \mathrm{H}_{2} \mathrm{O} \rightarrow \\
& \mathrm{Mn}_{0.5} \mathrm{Zn}_{0.5} \mathrm{Fe}_{2} \mathrm{O}_{4}+34.1 \mathrm{H}_{2} \mathrm{O}+13.32 \mathrm{CO}_{2}+4 \mathrm{~N}_{2}
\end{aligned}
$$

$$
\begin{aligned}
& 4.44 \mathrm{C}_{2} \mathrm{H}_{5} \mathrm{NO}_{2}+0.5 \mathrm{Mn}\left(\mathrm{NO}_{3}\right)_{2} \cdot 4 \mathrm{H}_{2} \mathrm{O} \\
& +2 \mathrm{Fe}\left(\mathrm{NO}_{3}\right)_{3} \cdot 9 \mathrm{H}_{2} \mathrm{O}+0.5 \mathrm{Zn}\left(\mathrm{NO}_{3}\right)_{2} \cdot 6 \mathrm{H}_{2} \mathrm{O} \rightarrow \\
& \mathrm{Mn}_{0.5} \mathrm{Zn}_{0.5} \mathrm{Fe}_{2} \mathrm{O}_{4}+34.1 \mathrm{H}_{2} \mathrm{O}+8.88 \mathrm{CO}_{2}+6.22 \mathrm{~N}_{2}
\end{aligned}
$$

$$
\begin{aligned}
& 6.66 \mathrm{CO}\left(\mathrm{NH}_{2}\right)_{2}+(0.5) \mathrm{Mn}\left(\mathrm{NO}_{3}\right)_{2} \cdot 4 \mathrm{H}_{2} \mathrm{O} \\
& +2 \mathrm{Fe}\left(\mathrm{NO}_{3}\right)_{3} \cdot 9 \mathrm{H}_{2} \mathrm{O}+0.5 \mathrm{Zn}\left(\mathrm{NO}_{3}\right)_{2} \cdot 6 \mathrm{H}_{2} \mathrm{O} \rightarrow \\
& \mathrm{Mn}_{0.5} \mathrm{Zn}_{0.5} \mathrm{Fe}_{2} \mathrm{O}_{4}+36.32 \mathrm{H}_{2} \mathrm{O}+6.66 \mathrm{CO}_{2}+10.66 \mathrm{~N}_{2}
\end{aligned}
$$

$\mathrm{Mn}_{0.5} \mathrm{Zn}_{0.5} \mathrm{Fe}_{2} \mathrm{O}_{4}$ were fabricated based on these ratios using different fuels and $\mathrm{pH}$, and the codes of fabricated samples are shown in Table1.

Table 1. Fuel type, $\mathrm{pH}$ and sample codes used in this study

\begin{tabular}{cccc}
\hline Sample & Fuel & pH & Sample codes \\
\hline \hline $\mathrm{Mn}_{0.5} \mathrm{Zn}_{0.5} \mathrm{Fe}_{2} \mathrm{O}_{4}$ & citric acid & 6 & $\mathrm{~S} 1$ \\
$\mathrm{Mn}_{0.5} \mathrm{Zn}_{0.5} \mathrm{Fe}_{2} \mathrm{O}_{4}$ & glycine & 3 & $\mathrm{~S} 3$ \\
$\mathrm{Mn}_{0.5} \mathrm{Zn}_{0.5} \mathrm{Fe}_{2} \mathrm{O}_{4}$ & urea & 0 & $\mathrm{~S} 4$ \\
\hline
\end{tabular}

All the samples were synthesized by the sol-gel combustion method using a magnetic stirrer and, after synthesis, the samples were calcined in the same condition at $500{ }^{\circ} \mathrm{C}$ and holding time 30 minutes. The average crystallite size of the samples was calculated from the peak broadening of ( $\left.\begin{array}{lll}3 & 1 & 1\end{array}\right)$ peak using Scherrer formula:

$$
D=0.9 \lambda /(\beta \cos \theta)
$$

Characterization of the synthesized powders was performed by using simultaneous thermal analysis (DTA-TG, model 503, BÄHR, Germany) in the argon gas atmosphere, X-ray diffraction (Siemens, D-500, Cu K $\alpha 1.54 \AA$ A, 30 kV, 2 degrees per $1 \mathrm{~min}$ ), vibration sample magnetometer (VSM) at $25{ }^{\circ} \mathrm{C}$ (Meghnatis Daghigh Kavir Co., Iran). Fourier transform infrared spectroscopy (FT-IR) of the samples was carried out using Spectrum RXI, PERKIN-ELMER SYSTEM, U.S, in the wavelength range of $400-4000 \mathrm{~cm}^{-1}$. The XRD results were studied by HighScore plus software, and 01-074-2401 and 01-074-2400 reference pdf file was used for identifying the spinel phase. The process of sample preparation was monitored by using a digital camera $(2048 \times 2048$ resolution $)$. For structural studies, transmission electron microscope (TEM: Zeiss - EM10C - $80 \mathrm{kV}$ ) and field emission scanning electron microscope (FE-SEM: Mira 3-XMU 700000 X) were used. 


\section{Results and discussion}

\subsection{Simultaneous thermal analysis}

Fig. 1 shows the DTA-TG curves of the powder synthesized with citric acid as a fuel. An increase in temperature led to changes in weight. In accordance with Fig. 1, minor weight loss occurred from room temperature to $400{ }^{\circ} \mathrm{C}(\max 1.4 \%)$ due to the removal of structural water and organic compounds remaining after combustion. The relatively intense peak shows the exothermic reaction [24]. With increasing temperature, the crystallization of the spinel phase has started above $400{ }^{\circ} \mathrm{C}$ [25]. A large part of the spinel phase has formed at the combustion stage, and an exothermic reaction with the release of energy during gel combustion occurred, which is confirmed by the broad peak. Massive weight loss, along with the occurrence of exothermic reaction at the combustion stage of the gel occurred [26], which is confirmed by the XRD patterns in Fig. 2 and Fig. 3. The endothermic reaction took place with an increase in temperature while the TG graph is flat and shows weight stability. DTA trace shows an exothermic reaction above $1000{ }^{\circ} \mathrm{C}$ with increasing inner oxygen pressure in the sample, and it is clear that controlling the amount of oxygen is very important to obtain pure $\mathrm{Mn}-\mathrm{Zn}$ ferrite [24].

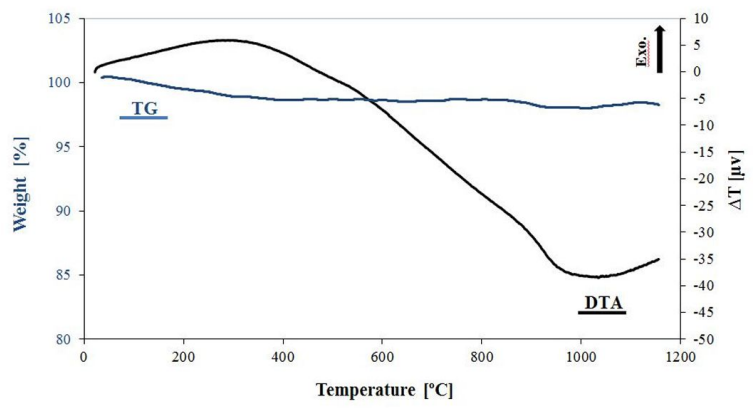

Fig. 1. TG-DTA curves of Mn-Zn ferrite synthesized with citric acid

\subsection{XRD analysis}

Fig. 2 shows the XRD patterns of the samples synthesized with three types of fuels. XRD curve of sample $\mathrm{S} 1$ shows a cubic spinel structure of the
Mn-Zn magnetic ferrite phase with some impurity phases. The broadness of all peaks indicates a typical characteristics of nanosized particles. In this sample, the maximum peak intensity is related to the (3 11 1) plane, but diffraction of (2 20$)$, (4 00 ), (4 $\left.4 \begin{array}{ll}4 & 0\end{array}\right)$ and (5 111 ) planes is also visible. On the other hand, the precipitation of the $\mathrm{Mn}_{2} \mathrm{O}_{3}$ phase near the $\left(\begin{array}{lll}4 & 0 & 0\end{array}\right)$ plane peak is also determined [1]. The average size of the crystallites crystallized in the sample synthesized with citric acid is about 28 nanometers. The sample prepared with glycine (S3) shows the formation of the major spinel phase ((2 20 ), (3 11 1), (4 40 0), and (5 11 1)) planes, which confirms the formation of the spinel phase [5]. The approximate average size of the crystallites calculated using the Scherrer formula is $11 \mathrm{~nm}$. The sample prepared using urea fuel (S4) also shows the same ((2 20$)$, ( $\left.\begin{array}{lll}3 & 1 & 1\end{array}\right),\left(\begin{array}{lll}4 & 4 & 0\end{array}\right)$, and (5 111$)$ ) planes peaks and confirms the formation of $\mathrm{Mn}-\mathrm{Zn}$ spinel ferrite too [27]. In this sample, the average crystallite size is estimated to be about $10 \mathrm{~nm}$. Some impurity peaks near (4 40 ) plane are also visible in sample S3 and $\mathrm{S} 4\left(2 \Theta=62^{\circ}\right)$

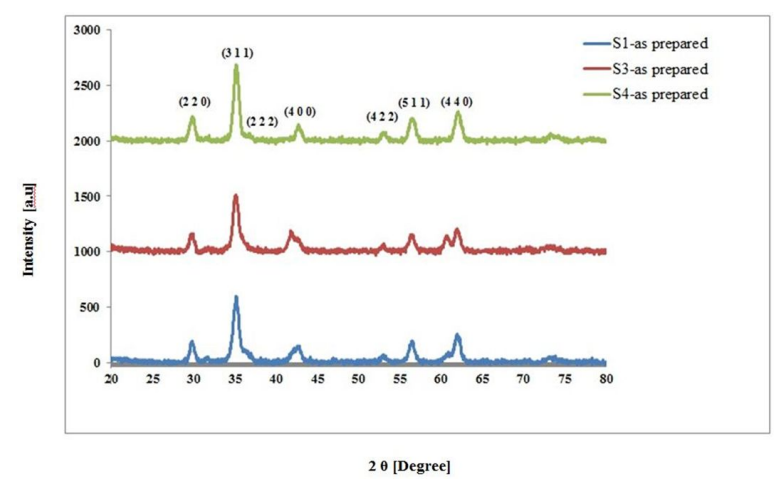

Fig. 2. XRD patterns of S1, S3, and S4 synthesized powders.

Fig. 3 shows the samples diffractograms after calcination in the same conditions. The XRD curves show the effect of solid-state reaction, on the morphology and impurities in magnetic phases. The sample synthesized with citric acid (S1) shows an increased intensity of (3 11 ), and (2 00 ) planes. In addition to the spinel phase, there are some impurity phases, such as $\mathrm{Fe}_{2} \mathrm{O}_{3}$ and $\mathrm{Mn}_{2} \mathrm{O}_{3}$ in the structure, which was also reported in litereture [24]. 
The calcination had the most significant effect on the S3 sample. An increase of spinel phase can be observed for the ( $\left.\begin{array}{lll}3 & 1 & 1\end{array}\right)$ plane peak, In fact, during synthesis by using glycine, the hematite nonmagnetic phase has changed and healed the defects in the spinel phase. This promoted the oxygen atoms diffusion into the spinel structure which led to the improvement in the magnetic properties of this sample [28]. Sample S4 also showed the effect of solid-state reaction after calcination. In this sample, different exothermic behavior of urea fuel led to the change in oxygen diffusion and reduced magnetic properties drastically due to the formation of a secondary hematite phase. The different morphology of the glycine-synthesized sample S3, as well as huge differences in the grain size, contributed to the difference in the magnetic properties of the samples [28]. It can be concluded that the calcination at the same temperature and time increased the spinel phase in the samples synthesized with citric acid and glycine, but in the samples synthesized by using urea, destructive structural change has been observed. The crystallite size after calcination was also calculated, and a change in its dimension was also observed. The average crystallite diameters were $48 \mathrm{~nm}, 18 \mathrm{~nm}$ and $16 \mathrm{~nm}$ for samples $\mathrm{S} 1, \mathrm{~S} 3$ and $\mathrm{S} 4$, respectively.

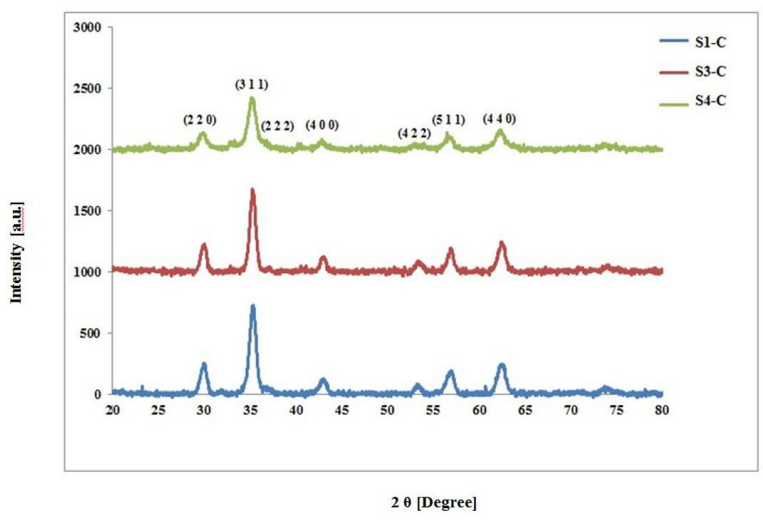

Fig. 3. XRD patterns of $\mathrm{S} 1, \mathrm{~S} 3$, and $\mathrm{S} 4$ samples after calcination at $500{ }^{\circ} \mathrm{C}$ for $30 \mathrm{~min}$

The oxygen parameter for an ideal spinel and FCC system should be 0.375 , and minor differences in the results of as-synthesized and calcined samples were observed. It was postulated that fuel type and processing parameters such as the synthesis and calcination conditions would affect this behavior. Lattice parameter and occupancy for all of the samples were calculated, and the results are shown in Table 2 and Table 3. The results reveal that lattice parameters of S4 sample is less than the those of the others, and calcination at high temperature decreases the lattice parameters of all samples.

Table 2. Lattice parameter and cation distribution in assynthesized powders

\begin{tabular}{ccc}
\hline Sample & $\begin{array}{c}\text { Lattice parameter } \\
{[\AA]}\end{array}$ & Occupancy \\
\hline \hline S1 & 8.4909 & 0.37203 \\
S3 & 8.4761 & 0.37148 \\
S4 & 8.4523 & 0.36721 \\
\hline
\end{tabular}

Table 3. Lattice parameter and cation distribution in calcined powders

\begin{tabular}{ccc}
\hline Sample & $\begin{array}{c}\text { Lattice parameter } \\
{[\AA]}\end{array}$ & Occupancy \\
\hline \hline S1 & 8.3995 & 0.37161 \\
S3 & 8.3905 & 0.366930 \\
S4 & 8.4140 & 0.39229 \\
\hline
\end{tabular}

Rietveld refinement of X-ray data shows cation ions distribution in all of the planes, especially in (3 11 1) one, and the results confirm the formation of the spinel phase [19]. According to Fig. 4 and Fig. 5, fuel type and calcination conditions have the most significant effect on how the ions are distributed and re-arranged in the spinel phase, which leads to a change in the magnetic properties of manganese-zinc ferrite.

\subsection{FT-IR analysis}

FT-IR analysis results were plotted in Fig. 6. The adsorption peaks at 547.36 and $557.4 \mathrm{~cm}^{-1}$ reveal the formation of the ferrite spinel phase and confirm the interaction of metal ions and oxygen with the occupied of octa-tetrahedral sites [29, 30]. Fig. 6 shows characteristic deformation vibrations and stretching of water molecules at $3434.54 \mathrm{~cm}^{-1}$ and $3417.74 \mathrm{~cm}^{-1}$, respectively 

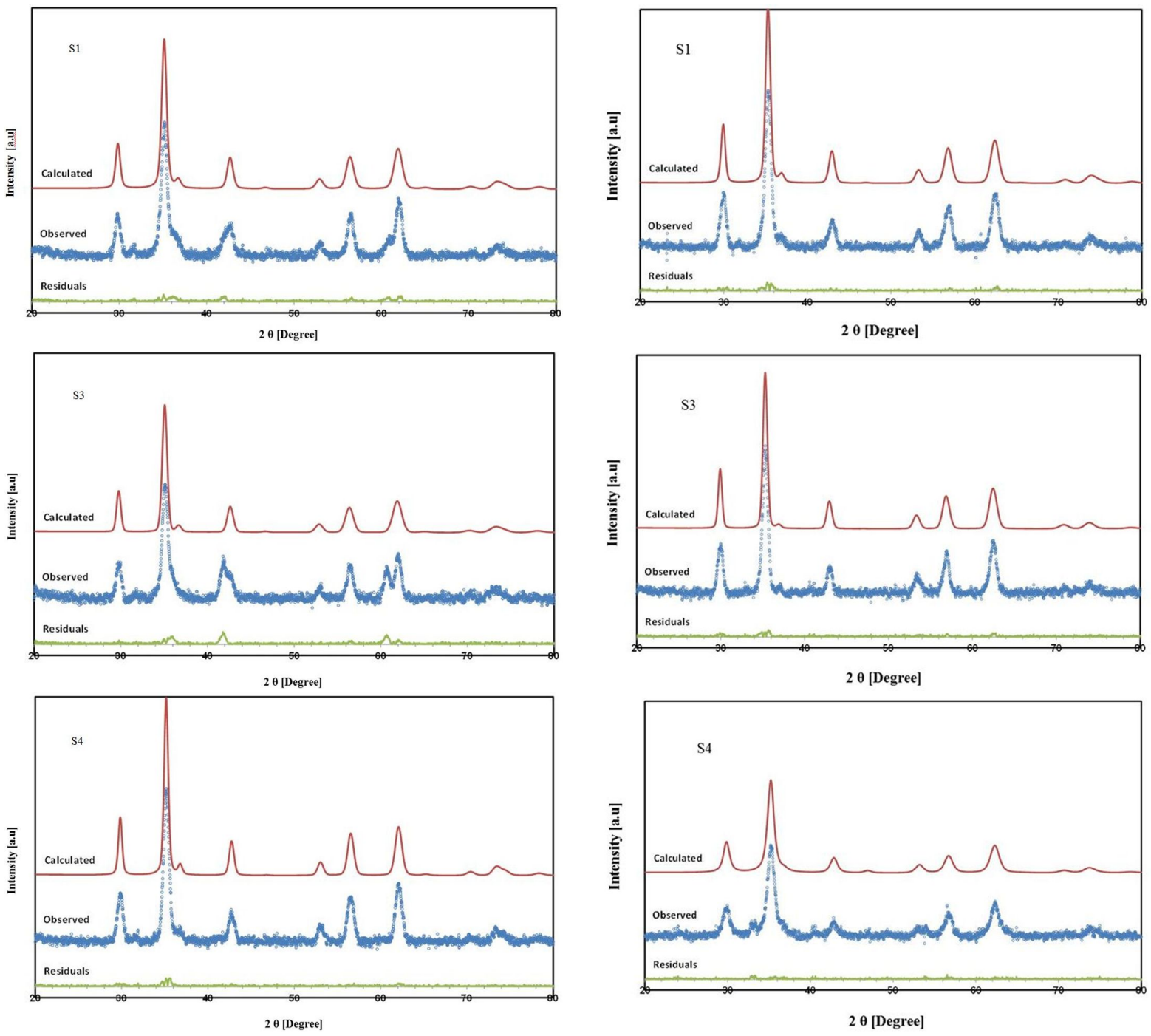

Fig. 4. Rietveld refinement of XRD patterns for asprepared powders

Fig. 5. Rietveld refinement of XRD patterns for calcined powders

for the as-synthesized sample and calcined powders. Water molecules caused the formation of agglomerates by crystallites incorporation. The vibration frequency of $\sim 1630 \mathrm{~cm}^{-1}$ can refer to carboxyl groups remaining after the combustion process [31]. Band vibration around $2350 \mathrm{~cm}^{-1}$ shows small absorption of atmospheric $\mathrm{CO}_{2}$ [31]. FT-IR spectra shown in Fig. 6 confirm the effect of calcination on the MZF.

\subsection{Process analysis}

Fig. 7 shows the images of samples $\mathrm{S} 1, \mathrm{~S} 3$, and S4 at various stages of preparation. Based on Fig. 7

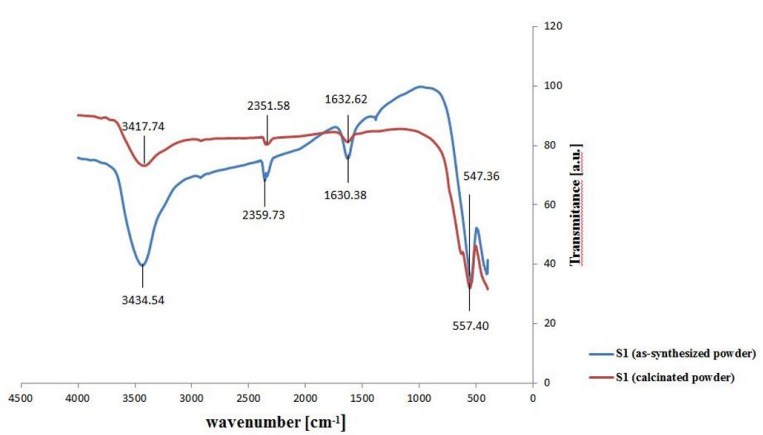

Fig. 6. FT-IR spectra of S1 sample as-synthesized and calcined 

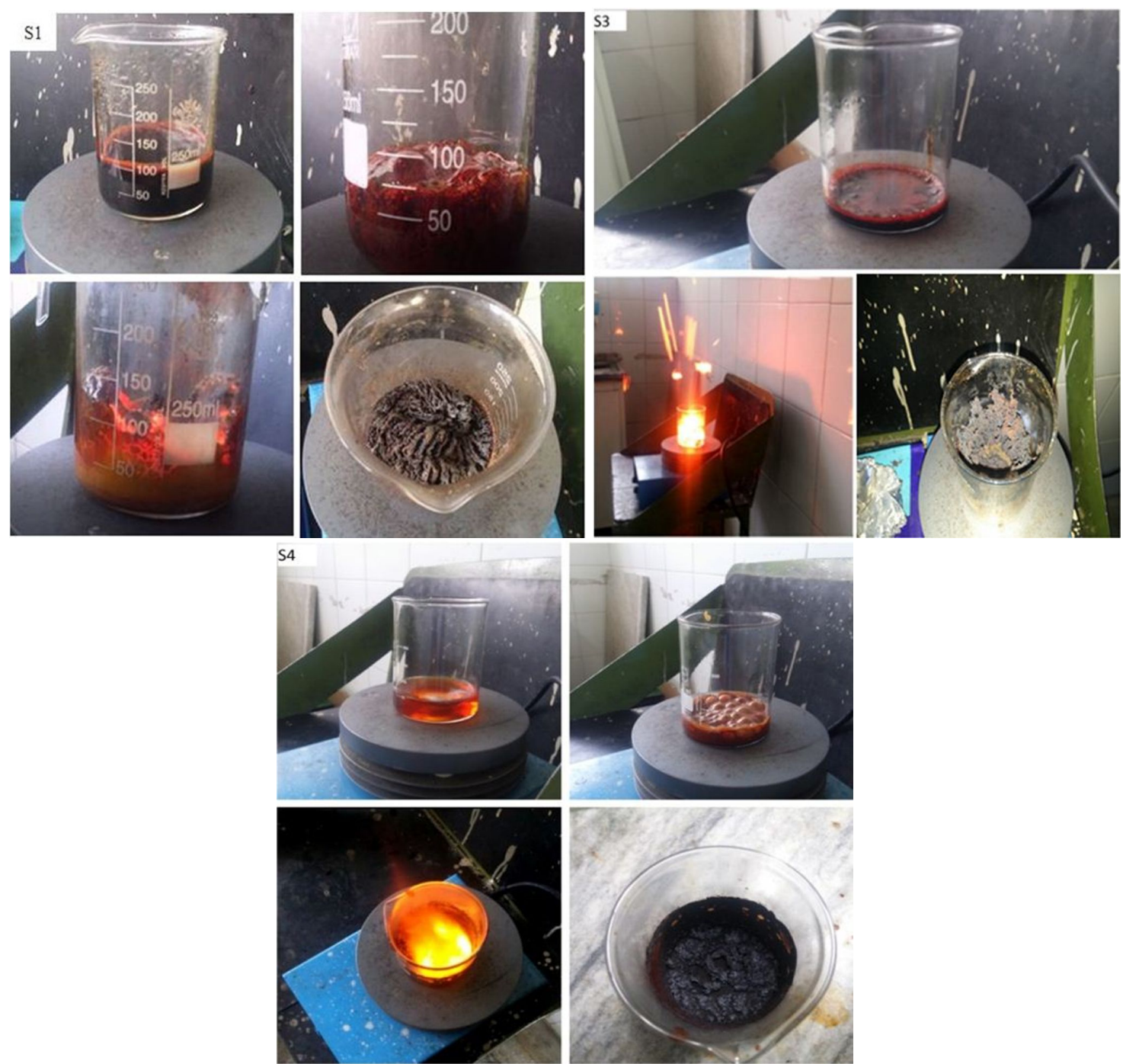

Fig. 7. Images of preparation steps of S1, S3, and S4 samples and influence of fuel on the combustion process.

results, the samples have shown similar trends during the process. In the combustion process, in all three samples, a gel has been formed between 70 and $80{ }^{\circ} \mathrm{C}$. The evaporation of a higher amount of water increased the gel density, and ignition took place after the complete removal of water around $220{ }^{\circ} \mathrm{C}$. A large portion of $\mathrm{CO}_{2}, \mathrm{CO}$, and $\mathrm{NO}_{2}$ was removed from the structure, and about $80 \%$ of weight loss after complete combustion took place [26]. Differences in the shape of flame were visible. The solution color became darker, depending on the fuel type and $\mathrm{pH}$ value. FT-IR spectra confirmed some molecular water remained in the structure after combustion and calcination processes.

\subsection{VSM analysis}

In Fig. 8, the curve for sample S1 shows the magnetic properties of the sample synthesized with citric acid fuel. Magnetic properties and magnetization of the produced nanoferrites depend on the factors such as $\mathrm{pH}$ and grain size, and it is clear that the magnetization is not completely saturated, which can be due to the unbalanced distribution of cations on the surface of the nanoparticles [1]. The magnetization of nanoferrite produced by using glycine fuel (sample S3) was also investigated. Significant differences with the previous example can be observed.The fuel type affected the magnetic properties significantly. The curve 
of sample S4 represents the magnetic properties of the sample synthesized with urea fuel, and the magnetic properties are much lower than those of the glycine synthesized ferrite. Factors such as the size of nanoparticles, density, and shape of agglomerates have a significant effect on the magnetic properties of manganese ferrites, and the particle size obtained in synthesis with glycine fuel is larger than the size of nanoparticles synthesized using urea fuel [28].

The values of magnetic saturation $\left(\mathrm{M}_{\mathrm{S}}\right)$, residual magnetization $\left(\mathrm{M}_{r}\right)$, and magnetic coercivity $\left(\mathrm{H}_{\mathrm{c}}\right)$ of the synthesized materials are collected in Table 4.

Table 4. Magnetic properties of Mn-Zn ferrites calcined at $500{ }^{\circ} \mathrm{C}$ for 30 minutes using different fuels

\begin{tabular}{ccccc}
\hline Sample & $\begin{array}{c}\mathrm{M}_{\mathrm{s}} \\
{[\mathrm{emu} / \mathrm{g}]}\end{array}$ & $\begin{array}{c}\mathrm{M}_{\mathrm{r}} \\
{[\mathrm{emu} / \mathrm{g}]}\end{array}$ & $\mathrm{M}_{\mathrm{r}} / \mathrm{M}_{\mathrm{s}}$ & $\mathrm{H}_{\mathrm{c}}\left[\mathrm{O}_{\mathrm{e}}\right]$ \\
\hline \hline $\mathrm{S} 1$ & 35.76 & 16.38 & 0.458 & 73 \\
$\mathrm{~S} 3$ & 57.89 & 23.32 & 0.4028 & 80.15 \\
S4 & 14.84 & 3.54 & 0.238 & 29.15 \\
\hline
\end{tabular}

\subsection{TEM analysis}

Fig. 9 shows a TEM micrograph of the asprepared sample with citric acid as a fuel. The image confirms the spherical morphology of the crystallites and agglomeration of the grains [32, 33]. The average grain size obtained from the TEM micrograph is consistent with the grain size calculated by using the Scherrer formula [13].

\subsection{FE-SEM analysis}

Fig. 10 shows FE-SEM images of calcined samples. In the $\mathrm{S} 1$ sample, the agglomerates and high density of nanoparticles are visible [24]. In this structure, the relatively uniform and large-size nanoparticles (up to about 100 nanometers) in the samples have been formed due to citric acid fuel reaction [34]. The uniformity of the particles may be related to molecular water removal during the reaction, which led to well-defined facets of some particles [31]. The image of the specimen $\mathrm{S} 3$ shows high density of nanoparticles in the produced sample. The amount of agglomerates is very high
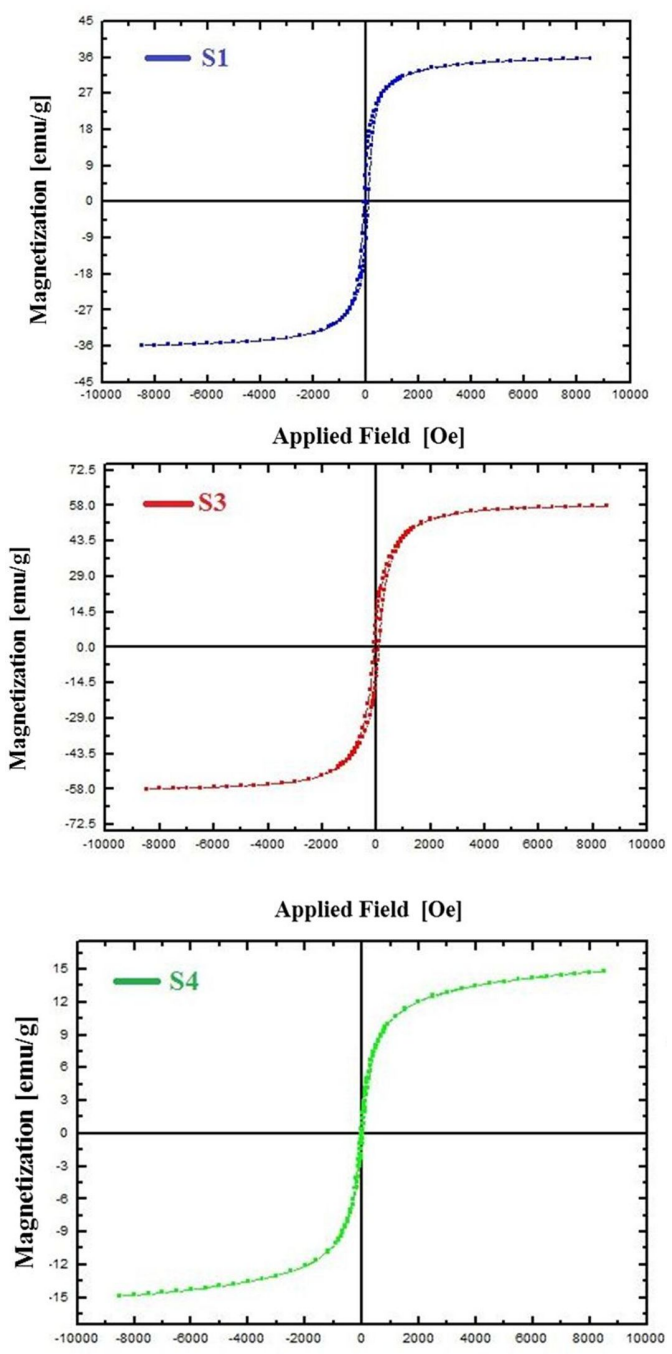

Applied Field [Oe]

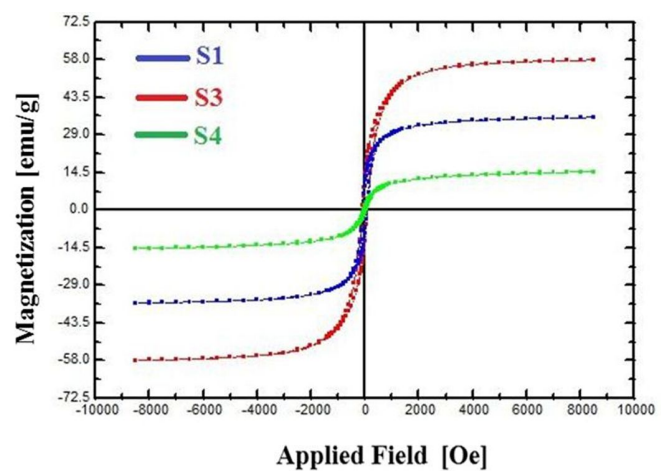

Fig. 8. VSM hysteresis curves for S1, S3, and S4 samples

because the particle size is very large, which results in superior magnetic properties of sample S3. The same morphology is also visible in the $\mathrm{S} 1$ sample. 


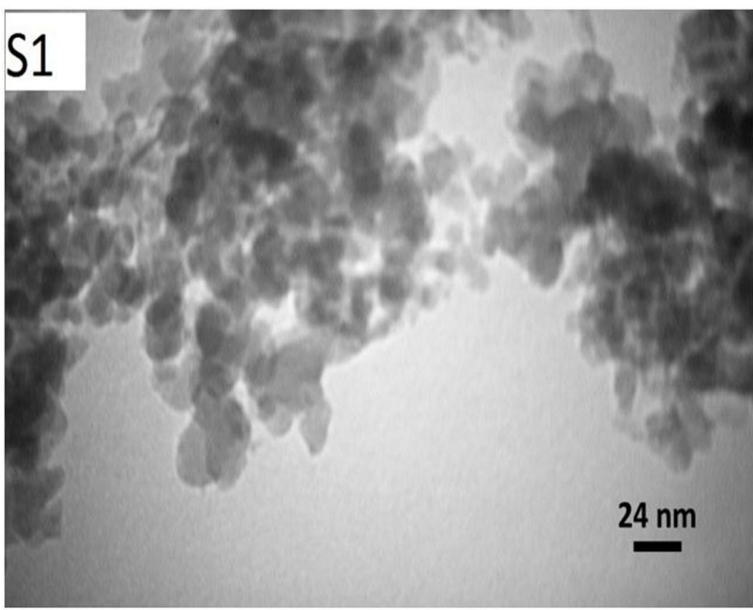

Fig. 9. TEM image of $S 1$ sample synthesized with citric acid.

The glycine-induced combustion produced spongelike structures in the specimen. In this case, stable primary agglomerates and secondary agglomerates have also been created. The sample synthesized with urea (S4), similar to the other samples, shows that agglomeration is the main phenomenon identified in the morphological study. Remarkable is the tiny size of the produced particles resulting from using the urea fuel. It can be observed that the particle size is of the order of $20 \mathrm{~nm}$ or less. From the images of sample $\mathrm{S} 4$, it can be concluded that, despite the agglomeration, the particles are not so dense and the adhesion between the particles is rather low, which can be related to the nature of urea and high-temperature conditions during the synthesis of samples by urea fuel [27].

\section{Conclusions}

Gel combustion method was employed to produce manganese-zinc nanoferrites with different structural and magnetic properties, which depended on the applied fuel. Using glycine resulted in nanoparticles with a porous structure, whereas urea and citric acid created a product with the smallest and the largest crystallite size, respectively. The samples synthesized with urea showed poor magnetic properties, and a minor secondary hematite phase developed there. According to VSM results, nanoparticles fabricated
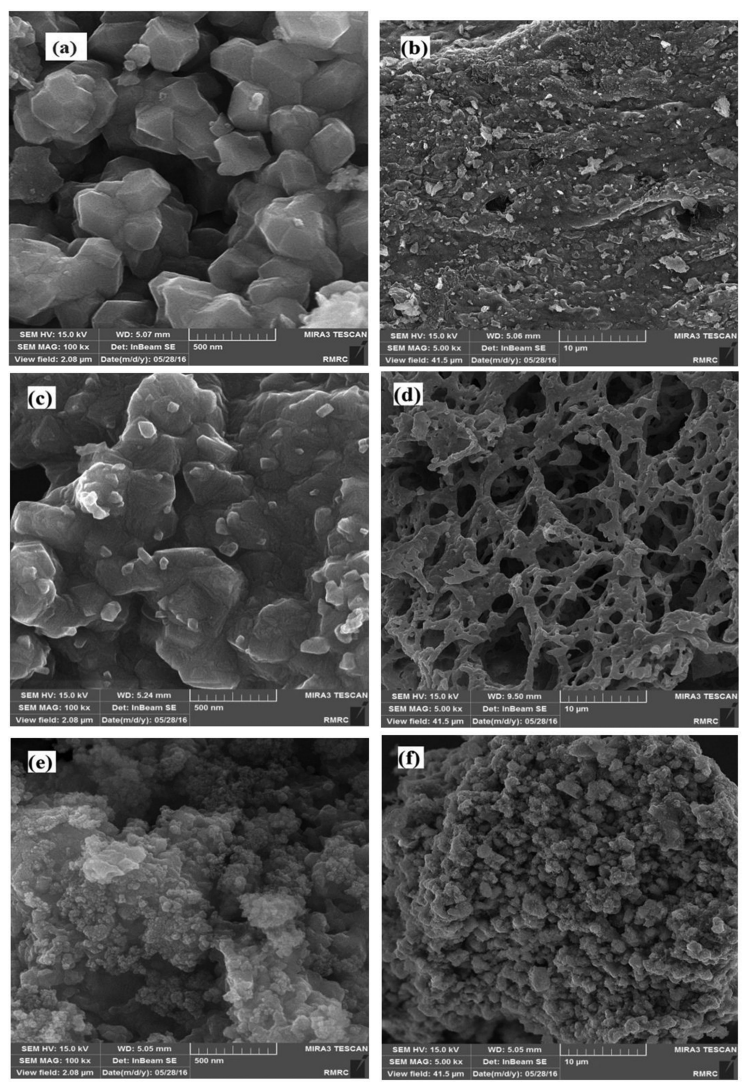

Fig. 10. FE-SEM images of $\mathrm{Mn}_{0.5^{-}} \mathrm{Zn}_{0.5}$ ferrites, (S1: (a, b); S3: (c, d) and S4: (e, f)). The images have been taken at different magnifications.

with glycine showed superior magnetic properties. Loose agglomerates of powders were formed after gel combustion synthesis due to fast and hightemperature reactions.

\section{References}

[1] Seyyed Ebrahimi S.A., Masoudpanah S.M., $J$. Magn. Magn. Mater, (2014), 77.

[2] Gimenes R., Baldissera M.R., DA Silva M.R.A., DA Silveira C.A., Soares D.A.W., Perazolli L.A., DA Silva M.R., Zaghete M.A., Ceram. Int, 1 (2012), 741.

[3] SutKa Andris., Mezinskis Gundars., Front. Mater. Sci, 2 (2012), 128.

[4] Ghobeiti Hasab M., Ebrahimi S.A., Badiei A., $J$. Non.-Cryst. Solids, 8-10 (2007), 814.

[5] Murugesan C., Mdgazzali P.M., ChanDrasekaran G., J. Mater. Sci.- Mater. El, 8 (2013), 3136.

[6] Hajarpour S., Gheisari KH., Honarbakhsh Raouf A., J. Magn. Magn. Mater, 329 (2013), 165. 
[7] TONOILO J.C., LIMA M.D., TAKIMI A.S., Bergmann C.P., Mater. Res. Bull, 3 (2005), 561.

[8] Vasanthi V., Shanmugavani A., Sanjeeviraja C., Kalai Selvan R., J. Magn. Magn. Mater, 13 (2012), 2100.

[9] Hwang C.C., Tsai J.S., Huang T.H., Mater. Chem. Phys, 2-3 (2005), 330.

[10] Pedzich Z., Bucko M.M., Krolikowski M., Bakalarska M., Babiarz J., J. Eur. Ceram. Soc, 6 (2004), 1053.

[11] Hou J.G., Qu Y.F., MA W.B., Sun Q.C., J. Sol.-Gel. Sci. Techn, 1 (2007), 15.

[12] Bakhshi H., Shokuhfar A., Seyyed Afghahi S.S., Ceram. Int, 9 (2015), 10736.

[13] Motevalian A., Salem S., Particuology, (2016), 108.

[14] Mohamed R.M., Rashad M.M., Haraz F., SigMUND W., J. Magn. Magn. Mater, 14 (2010), 2058.

[15] Rasly M., Rashad M.M., J. Magn. Magn. Mater, (2013), 58

[16] Rashad M.M., Turky A.O., Kandil A.T., J. Mater. Sci.- Mater. El, 9 (2013) 3284.

[17] Rashad M.M., J. Mater. Sci.- Mater. El, 4 (2012), 882.

[18] Bahadur D., Rajakumar S., Kumar A., J. Chem. Sci, 1 (2006), 15.

[19] Abu El Fadl A., Hassan A.M., Mahmoud M.H., TATARChUK T., YAREMIY I.P., Gismelssed A.M., Ahmed M.A., J. Magn. Magn. Mater, (2019), 192.

[20] Ahmed M.A., Hassan H.E., Eltabey M.M., Latla K., Tatarchuk T.R., Physica. B, (2018), 195.

[21] Rajesh Babu B., Tatarchuk T., Mater. Chem. Phys, (2018) 534.

[22] Kane S.N., Raghuvanshi S., Satalkar M., REDDY V.R., DEShPANDE U.P., TATARCHUK T.R., Mazaleyrat F., AIP. Conf. Proc, 1 (2018), 030089.
[23] Tatarchuk Tetiana., Bououdina M., Judith ViJAYA J., JOHN KENNEDY L., Nanophysics, Nanomaterials, Interface Studies, and Applications, Springer, Lviv, 2016.

[24] Hu P., Yang H.B., Pan D.A., Wang H., Tian J.J., Zhang S.G., WANG X.F., A.Volinsky A., J. Magn. Magn. Mater, 1 (2010) 173.

[25] Bakhshi H., Shokuhfar A., Vahdati N., Int. $j$. Min. Met. Mater, 9 (2016), 1104.

[26] Waqas H., Qureshi A.H., J. Therm. Anal. Calorim, 2 (2009), 355.

[27] Costa A.C.F.M, Morelli M.R., Kiminami R.H., J. Mater. Synth. Process, 6 (2001), 347.

[28] Costa A.C.F.M., Silva V.J., Xin C.C., Viera D.A., Cornejo D.R., Kiminami R.H.G.A., J. Alloy. Compd, 2 (2010), 503.

[29] TAtarchuk T.R., Bououdina M., Paliychuk N.D., Yaremiy I.P., Moklyak V.V., J. Alloy. Compd, (2017), 777.

[30] Tatarchuk T.R., Paliychuk N.D., Bououdina M., Al Najar B., PACia M., MacyK W., ShyichunK A., J. Alloy. Compd, (2018), 1256.

[31] Szczygiel I., Winiarska K., Bien Ko A., Suracka K., Gaworska Koniarek D., J. Alloy. Compd, (2014), 1.

[32] Maensiri S., Chivalrat M., Boonchom B., Seraphin Supapan., Scripta. Mater, 9 (2007), 797.

[33] Gabal M.A., Abdel Daiem A.M., Al Angari Y.M., ISMAIL I.M., Polyhedron, (2013), 105.

[34] Wang W., Zang C., JiaO Q., J. Magn. Magn. Mater, (2014), 116. 